Article

\title{
Shape Memory Behavior of Carbon Black-reinforced Trans-1,4-polyisoprene and Low-density Polyethylene Composites
}

\author{
Lin Xia ${ }^{1}{ }^{1}$, Han Gao ${ }^{1}$, Weina Bi ${ }^{1}$, Wenxin Fu ${ }^{2}$, Guixue Qiu ${ }^{1, *}$ and Zhenxiang Xin ${ }^{1}$ \\ 1 Key Laboratory of Rubber-Plastics, Ministry of Education/Shandong Provincial Key Laboratory of \\ Rubber-Plastics, School of Polymer Science and Engineering, Qingdao University of Science and Technology, \\ Qingdao 266042, China; xialin@qust.edu.cn (L.X.); 13306383978@163.com (H.G.); \\ biweina1981@163.com (W.B.); xinzhenxiang@126.com (Z.X.) \\ 2 Materials Science and Engineering, School of Engineering, University of California at Merced, 5200 North \\ Lake Road, Merced, CA 95343, USA; wfu7@ucmerced.edu \\ * Correspondence: qiugx@163.com
}

Received: 21 March 2019; Accepted: 15 April 2019; Published: 6 May 2019

\begin{abstract}
Shape memory composites of trans-1,4-polyisoprene (TPI) and low-density polyethylene (LDPE) with easily achievable transition temperatures were prepared by a simple physical blending method. Carbon black (CB) was introduced to improve the mechanical properties of the TPI/LDPE composites. The mechanical, cure, thermal and shape memory properties of the TPI/LDPE/CB composites were investigated in this study. In these composites, the crosslinked network generated in both the TPI and LDPE portions acted as a fixed domain, while the crystalline regions of the TPI and LDPE portions acted as a reversible domain in shape memory behavior. We found the mechanical properties of composites were promoted significantly with an increase of CB content, accompanied with the deterioration of shape memory properties of composites. When CB dosage was 5 parts per hundred of rubber composites ( $\mathrm{phr}$ ), best shape memory property of composites was obtained with a shape fixity ratio of $95.1 \%$ and a shape recovery ratio of $95.0 \%$.
\end{abstract}

Keywords: trans-1,4-polyisoprene; low-density polyethylene; carbon black; shape memory; reinforce

\section{Introduction}

Shape memory polymers (SMPs) are smart stimuli responsive materials [1], which possess the capacity to fix temporary shapes and recover to their permanent shapes under external stimulus, such as moisture, heat, $\mathrm{pH}$, light, electric and magnetic fields [2-8]. With merits of low manufacturing costs, tunable recovery temperature and possible biocompatibility, heat stimuli responsive SMPs have had extensive advances in both academic and industrial fields, which has granted this kind of smart material wide potential applications, such as in deployable aerospace structures, intelligent textiles, self-healing and biomedical devices [9-14].

Generally, SMPs are multiphase materials, which are comprised of fixed and reversible domains. Fixed domains are usually used to sustain permanent shapes by restricting plastic slippage of SMPs molecule chains, which could be hydrogen bonding, chain entanglement or chemical cross-linked points [15]. The crystalline regions or soft chain segment of polymers could work as reversible domains [16,17]. And reversible domains are utilized to obtain temporary shapes by freezing and unfreezing around transition temperatures $\left(T_{\text {trans }}\right)[18]$, which may be melting temperature $\left(T_{m}\right)$ for crystalline polymers or glass transition temperatures $\left(\mathrm{T}_{\mathrm{g}}\right)$ for amorphous polymers. Shape memory process of SMPs was described as follows [19]: First, the SMPs specimens were stretched at a temperature above $T_{\text {trans }}$ with mechanical load applied. Second, stretched specimens were cooled at a 
certain rate without a mechanical load. The temporary shapes were generated and entropic elasticity was restored in the polymer matrix in this process. Finally, permanent shapes of SMPs were recovered when specimens were reheated above $T_{\text {trans, }}$ which was attributed to the entropic elasticity released from polymer matrix. The molecule chains with regular arrangement in specimens tended back to its random stages when specimens were reheated again.

Compared to other shape memory materials, such as shape memory ceramics (SMCs) and alloys (SMAs), SMPs exhibit excellent qualities as a high recoverable strain, controllable mechanical properties and easily shaped properties [20-23]. However, low recovery stress and poor mechanical properties of SMPs limit the applications of SMPs. Trans-1,4-polyisoprene (TPI) is a typical SMP when it is partly cross-linked, which is similar to cross-linked polyethylene (PE) [24,25]. The shape memory properties of TPI, PE and their blends have been investigated in recent years [26,27]. However, the disadvantage of most shape memory composites is their poor mechanical properties, and TPI and PE composites are no exception. Therefore, improving the mechanical properties of SMPs is a very important topic. Carbon black, as a common reinforcement filler, is widely utilized in the rubber industry with advantages of moderate pricing and extensive available sources [28-32]. Carbon black could also be used in conductive and functional sensing fields $[33,34]$. In this paper, carbon black (CB) reinforced shape memory composites of TPI and low-density PE (LDPE) were prepared by a mechanical blending method. The effect of $\mathrm{CB}$ on the mechanical, thermal and shape memory properties of composites were investigated in this manuscript. And a schematic diagram was proposed to illustrate the shape memory behavior of the TPI/LDPE composites. These kinds of composites are expected to be used as pipe connection materials, especially in heat shrinkable PE pipe connect parts.

\section{Experimental}

\subsection{Materials}

LDPE (type LD100AC) pellets with melt flow index (MFI) of $2.1 \mathrm{~g}(10 \mathrm{~min})^{-1}\left(190^{\circ} \mathrm{C}\right)$ were purchased from Yan-shan Petrochemical Co Ltd (Beijing, China). TPI powder (purity $\geq 99 \%$ ) with a Mooney viscosity of 103.3 was purchased from Di Pai New Material Co Ltd (Qingdao, China). Carbon black (type N330) with an average particle diameter of $30 \mathrm{~nm}$ was purchased from Cabot Co Ltd (Shanghai, China). Rubber antioxidant 2-mercaptobenzimidazole (MB) was purchased from Xuzhou Lejin Chemical Technology Co Ltd (Xuzhou, China). Dicumyl peroxide (DCP) was purchased from Akzo Nobel polymer Chemicals (Ningbo, China). Other additives were obtained from commercial sources and were used without further purification.

\subsection{Preparation of the TPI/LDPE/CB Composites}

The LDPE, TPI and CB were dried in a vacuum oven at $50^{\circ} \mathrm{C}$ for $6 \mathrm{~h}$ before use. The TPI/LDPE composites with different $\mathrm{CB}$ doses were prepared on a high-temperature open mill at $110{ }^{\circ} \mathrm{C}$ for 10 min with a standard mixing sequence. The composite formulations with different $\mathrm{CB}$ doses are shown in Table 1.

Table 1. Formulations of TPI/LDPE/CB composites (parts per hundred of rubber).

\begin{tabular}{ccccc}
\hline Chemicals & A & B & C & D \\
\hline TPI & 60 & 60 & 60 & 60 \\
LDPE & 40 & 40 & 40 & 40 \\
DCP & 0.4 & 0.4 & 0.4 & 0.4 \\
Antioxidant MB & 1.5 & 1.5 & 1.5 & 1.5 \\
CB (N330) & 0 & 5 & 10 & 15 \\
\hline
\end{tabular}




\subsection{Cure Characteristics of the Composites}

The cure characteristics of the composites were studied with a Monsanto oscillating disc rheometer (Monsanto Company, St. Louis, MO, USA) at $170{ }^{\circ} \mathrm{C}$ according to ASTM D-2084-07. The optimum cure time, scorch time and cure rate index were determined, and are presented in Table 2.

Table 2. Effect of carbon black (CB) dosage on cure characteristics of TPI/LDPE composites.

\begin{tabular}{ccccc}
\hline \multirow{2}{*}{ Properties } & \multicolumn{4}{c}{ Dosage of CB (N330) } \\
\cline { 2 - 5 } & A & B & C & D \\
\hline $\mathrm{M}_{\mathrm{H}}(\mathrm{dN} \cdot \mathrm{m})$ & 4.95 & 5.79 & 6.66 & 7.61 \\
$\mathrm{M}_{\mathrm{L}}(\mathrm{dN} \cdot \mathrm{m})$ & 2.06 & 2.42 & 2.68 & 2.99 \\
$\mathrm{M}_{\mathrm{H}}-\mathrm{M}_{\mathrm{L}}(\mathrm{dN} \cdot \mathrm{m})$ & 2.89 & 3.37 & 3.98 & 4.62 \\
$\mathrm{~T}_{10}(\mathrm{~min})$ & 1.30 & 1.15 & 1.07 & 1.03 \\
$\mathrm{~T}_{90}(\mathrm{~min})$ & 16.00 & 13.67 & 13.02 & 11.83 \\
Cure rate index $\left(\mathrm{min}^{-1}\right)$ & 6.80 & 7.99 & 8.37 & 9.26 \\
\hline
\end{tabular}

\subsection{Mechanical Characterization}

Vulcanized slabs were prepared by compression molding, and the dumbbell shaped specimens were punched out from a molded sheet by using an ASTM Die C (Wuxi KLT Precision Hydraulic Machinery Factory, Wuxi, China). The tests were conducted following ASTM D 412-06 and ASTM D 624-00 (2007). The modulus at $100 \%$ and 300\%, elongation, tensile strength, tear strength and elongation at break were measured at room temperature. The initial length of the specimen was $25 \mathrm{~mm}$, and the speed of the jaw separation was $500 \mathrm{~mm} \mathrm{~min}^{-1}$.

\subsection{Differential Scanning Calorimetry (DSC)}

The thermal properties of the blends were determined using a DSC-Q20 calorimeter (TA Instruments, New Castle, Delaware, USA) under a nitrogen atmosphere. The temperature and enthalpy were calibrated with an indium standard. Samples with a mass of 5-10 mg were maintained at $130^{\circ} \mathrm{C}$ for $3 \mathrm{~min}$ to eliminate their thermal history before they were cooled to $-50^{\circ} \mathrm{C}$ at $10{ }^{\circ} \mathrm{C} \mathrm{min}-1$. The samples were subsequently heated to $130{ }^{\circ} \mathrm{C}$ at $10{ }^{\circ} \mathrm{C} \mathrm{min}{ }^{-1}$. Traces of the first cooling and second heating steps were recorded for analysis. The degree of crystallinity $\left(X_{c}\right)$ for each portion of sample was calculated by the following equation:

$$
X c=\frac{\Delta H m}{\Delta H m^{*}} \times 100 \%
$$

where $\Delta \mathrm{H}_{\mathrm{m}}$ and $\Delta \mathrm{H}_{\mathrm{m}}{ }^{*}$ are the melting enthalpy of a certain polymer portion and its perfect melting enthalpy (ca. $186.8 \mathrm{~J} \mathrm{~g}^{-1}$ for TPI and ca. $277.1 \mathrm{~J} \mathrm{~g}^{-1}$ for LDPE), respectively.

\subsection{Shape Memory Effect}

The shape memory properties of the composites were analyzed by a DMA-Q800 instrument (TA Instruments, New Castle, Delaware, USA) in the Controlled Force' mode. The preloading was $0.001 \mathrm{~N}$, and the frequency was $1 \mathrm{~Hz}$. The test samples with a thickness of $2.0 \mathrm{~mm}$ were cut into rectangular shapes with a width of $4.0 \mathrm{~mm}$ and length of $30.0 \mathrm{~mm}$. The initial clamp gap was set to $6.0 \sim 8.0 \mathrm{~mm}$. The heating and cooling rates were both $5{ }^{\circ} \mathrm{C} \mathrm{min}^{-1}$. The procedures for determining the shape memory effect are described below.

First, the sample was maintained isothermally at $130{ }^{\circ} \mathrm{C}$ for 5 min to completely melt the crystalline regions of both TPI and LDPE (the initial strain was denoted $\varepsilon_{0}$ ). Second, a mechanical load of $0.2 \mathrm{MPa}$ was applied, and the sample was cooled to $-20{ }^{\circ} \mathrm{C}$ at $5{ }^{\circ} \mathrm{C} \mathrm{min}^{-1}$ to completely freeze the crystalline domain $\left(\varepsilon_{1, \text { load }}\right)$. After removal of the mechanical load, the sample was maintained 
at $-20{ }^{\circ} \mathrm{C}$ isothermally for $5 \mathrm{~min}\left(\varepsilon_{1}\right)$. Finally, the sample was reheated to $130{ }^{\circ} \mathrm{C}$ at $5{ }^{\circ} \mathrm{C} \min ^{-1}$ and maintained isothermally for $15 \mathrm{~min}\left(\varepsilon_{0, \text { rec }}\right)$.

The shape fixity ratio $\left(R_{f}\right)$ and shape recovery ratio $\left(R_{r}\right)$ are crucial parameters for SME characterization. The $R_{f}$ for the temporary shape $1\left(R_{f}(0 \rightarrow 1)\right)$ and the $R_{r}$ for the recovery from temporary shape 1 to $0\left(\mathrm{R}_{\mathrm{r}}(1 \rightarrow 0)\right)$ are quantified as follows [35-37]:

$$
\begin{aligned}
& R_{f}(0 \rightarrow 1)=\frac{\varepsilon_{1}-\varepsilon_{0}}{\varepsilon_{1, \text { load }}-\varepsilon_{0}} \times 100 \% \\
& R_{r}(1 \rightarrow 0)=\frac{\varepsilon_{1}-\varepsilon_{0, \text { rec }}}{\varepsilon_{1}-\varepsilon_{0}} \times 100 \%
\end{aligned}
$$

where $\varepsilon_{\text {load }}$ represents the maximum strain under the load, $\varepsilon$ is the strain after cooling and load removal, and $\varepsilon_{\text {rec }}$ is the recovered strain.

\section{Result and Discussion}

\subsection{Curing, Mechanical Properties}

First, we studied the effect of the CB dose on cure characteristics (Table 2). Dicumyl peroxide (DCP) is a peroxide vulcanizing agent, which not only vulcanized TPI containing double bonds, but also crosslinked LDPE without double bonds. Therefore, under the action of DCP, the composite would form a TPI cross-linking phase, a LDPE cross-linking phase, a TPI and a LDPE co-cross-linking phase. The scorch time $\left(T_{10}\right)$ and optimum cure time $\left(T_{90}\right)$ were gradually shortened as the $C B$ dose was increased. The values of $\mathrm{M}_{\mathrm{H}}-\mathrm{M}_{\mathrm{L}}$, the reflection of crosslinking extent of composites, increased with an increasing $\mathrm{CB}$ content. Besides the generation of cross-link network under the fixed dosage of DCP, the aggregation of $\mathrm{CB}$ particles was also responsible for melt viscosity improvement of composites. The baffle effect on melt viscosity of TPI/LDPE composites was amplified by the massive CB dosage. Meanwhile, oxygen-containing groups (such as hydroxyl and carboxyl) on the surface of CB particles might act as an accelerator agent in the cross-linking reaction. Therefore, the scorch time $\mathrm{T}_{10}$ and optimum cure time $\mathrm{T}_{90}$ of composites were shortened as $\mathrm{CB}$ dosage increased.

Next, we tested the mechanical properties of the composites (Table 3). We found that all mechanical performance indexes were improved notably by CB incorporation. Especially, when the carbon black content was $15 \mathrm{phr}$, the tensile strength and tearing strength of composites were increased about $5 \mathrm{MPa}$ and $10 \mathrm{kN} / \mathrm{m}$, respectively. We speculated that chemical and physical cross-linkages were both contributed to this phenomenon. Chemical cross-linkage, which generated by DCP, provided chemical bonding for molecule chains of the polymer matrix. But this enhancement effect remained constant due to the fixed DCP content. The physical cross-linkage generated by interactions between CB particles and molecule chains of polymer matrix promoted the mechanical properties of composites, which became excellent with the increase of CB content.

Table 3. Effect of CB dosage on mechanical properties of TPI/LDPE composites.

\begin{tabular}{ccccc}
\hline \multirow{2}{*}{ Properties } & \multicolumn{4}{c}{ Dosage of CB (N330) } \\
\cline { 2 - 5 } & A & B & C & D \\
\hline Tensile strength $(\mathrm{MPa})$ & 14.9 & 17.3 & 18.5 & 19.8 \\
100\% modulus $(\mathrm{MPa})$ & 7.4 & 8.3 & 8.4 & 8.6 \\
300\% modulus $(\mathrm{MPa})$ & 9.7 & 11.4 & 11.7 & 12.5 \\
Elongation at break $(\%)$ & 575 & 567 & 602 & 612 \\
Tear strength $(\mathrm{kN} / \mathrm{m})$ & 69.2 & 76.2 & 78.2 & 79.4 \\
\hline
\end{tabular}

\subsection{DSC Analysis}

Both TPI and LDPE easily crystallize due to their regular macromolecular chain structures. The addition of $\mathrm{CB}$ would affect not only the mechanical properties but also the thermal properties of 
the materials. Therefore, it is very important to investigate the effect of $\mathrm{CB}$ on the crystallization of composites. Both the thermal properties and transition temperatures of the shape memory composites can be measured by DSC. The effect of CB dosage on melting temperature ( $\left.\mathrm{T}_{\mathrm{m}}\right)$, peak position and crystallinity of composites were investigated and shown in Figure 1 and Table 4. We found the peak positions for melting and crystallizing temperature remained almost constant, which might be attributed to the fixed dosage of cross-link agent (DCP). However, melting enthalpies for each portion of composites were elevated slightly then decreased as CB dosage increased. The increase of melting enthalpies might be due to the crystallization nucleation effect of $C B$ in composites. However, the flexibility of polymer molecular chains would be impaired leading to the reduction of crystallinity degree of TPI and LDPE portions when CB dosage reached to high value.
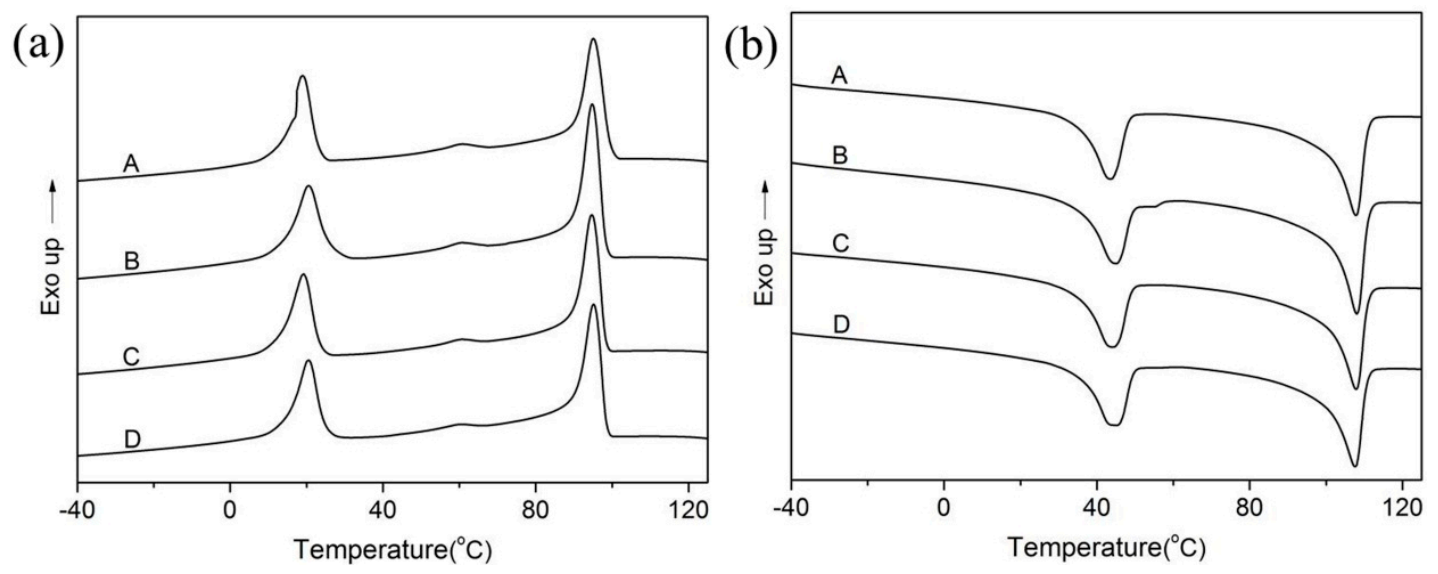

Figure 1. Effect of CB dosage on DSC curves of TPI/LDPE composites, (a) cooling curves and (b) heating curves.

Table 4. Effect of CB dosage on crystallinity of TPI/LDPE composites.

\begin{tabular}{ccccc}
\hline \multirow{2}{*}{ Properties } & \multicolumn{4}{c}{ Dosage of CB (N330) } \\
\cline { 2 - 5 } & A & B & C & D \\
\hline $\mathrm{X}_{\mathrm{c}(\mathrm{TPI})}(\%)$ & 12.3 & 14.4 & 13.7 & 12.7 \\
$\mathrm{~T}_{\mathrm{m}(\mathrm{TPI})}\left({ }^{\circ} \mathrm{C}\right)$ & 35.19 & 35.45 & 34.95 & 35.61 \\
$\Delta \mathrm{H}_{\mathrm{m}(\mathrm{TPI})}(\mathrm{J} / \mathrm{g})$ & 22.91 & 26.91 & 25.62 & 23.78 \\
$\mathrm{X}_{\mathrm{c}(\mathrm{LDPE})}(\%)$ & 13.4 & 14.7 & 14.4 & 13.1 \\
$\mathrm{~T}_{\mathrm{m}}(\mathrm{LDPE})\left({ }^{\circ} \mathrm{C}\right)$ & 99.87 & 100.40 & 99.46 & 99.02 \\
$\Delta \mathrm{H}_{\mathrm{m}(\mathrm{LDPE})}(\mathrm{J} / \mathrm{g})$ & 37.02 & 40.79 & 39.89 & 36.37 \\
$\mathrm{X}_{\mathrm{c}(\mathrm{TPI}+\mathrm{LDPE})}(\%)$ & 25.7 & 29.1 & 28.1 & 25.8 \\
\hline
\end{tabular}

\subsection{Shape Memory Effect Analysis}

Finally, shape memory properties of TPI/LDPE/CB composites were measured by a dynamic mechanical analyzer (Figure 2 and Table 5). Specimens of SMPs was kept isothermally above $T_{\text {trans }}$ $\left(130^{\circ} \mathrm{C}\right)$. The crystalline regions of TPI and LDPE were both melted, which acted as reversible domains in composites. Meanwhile, the cross-linking network acted as fixed domain to restrict plastic slippage of molecular chains. We found the addition of $\mathrm{CB}$ could improve the shape memory recovery ratio partly. The shape recovery ratio $\left(R_{r}\right)$ of composites was improved from $88.6 \%$ to $95.0 \%$ with the addition of $\mathrm{CB}$ filler $(5 \mathrm{phr})$. The shape fixity ratio $\left(\mathrm{R}_{\mathrm{f}}\right)$ of composites changed little and kept above $91 \%$. The improvement of $R_{r}$ was due to the physical network generated by introducing CB, which provided additional entropic elasticity restored in specimens during the shape memory test. Meanwhile, crystalline property of TPI/LDPE composites were improved by adding a small amount of CB (5 phr), which made proper proportion between fixed and reversible domains. The formation of CB physical network and increase of crystallinity of polymer phase resulted in the improvement of shape memory 
property of composites. However, $\mathrm{R}_{\mathrm{f}}$ and $\mathrm{R}_{\mathrm{r}}$ showed decreasing tendencies, when $\mathrm{CB}$ dosage was elevated again. Obviously, relatively high dosages of CB (10 phr and $15 \mathrm{phr})$, accompanied with enhancement of physical cross-linkage, was harmful for reservation of the shape memory effect (SME) by producing a low crystallinity of polymer matrix and bad chain flexibility. However, the addition of CB improved the total crystallinity of TPI and LDPE components in composites (Table 4). Therefore, the addition of a large dose of $\mathrm{CB}$ still improved the shape memory properties of composites compared with those without CB.

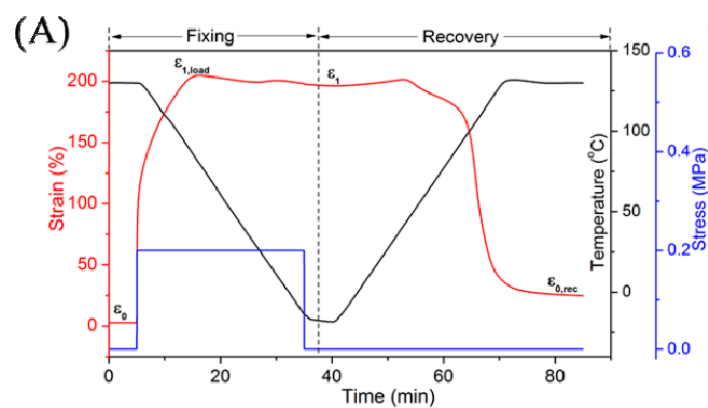

(C)

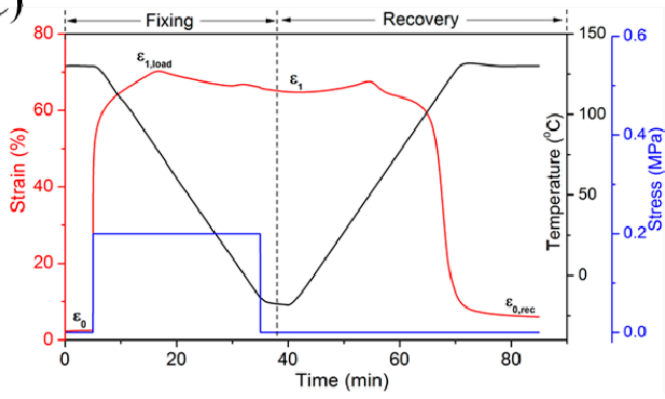

(B)

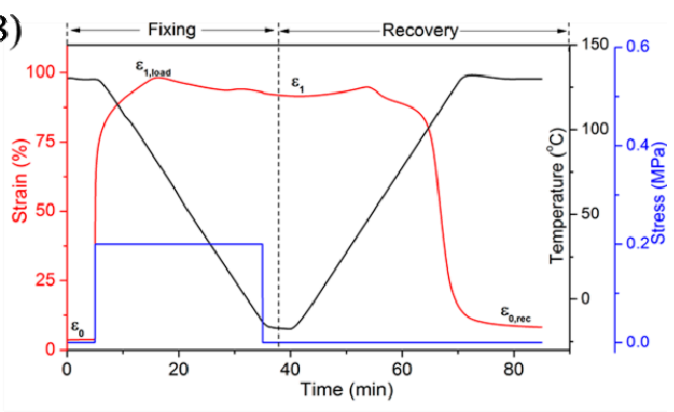

(D)

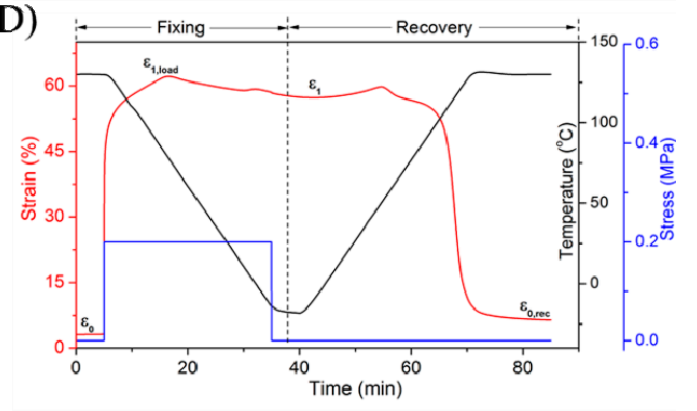

Figure 2. Effect of CB dosage on shape memory properties of TPI/LDPE blends.

Table 5. Effect of CB dosage on shape memory properties of TPI/LDPE composites.

\begin{tabular}{ccccc}
\hline \multirow{2}{*}{ Properties } & \multicolumn{4}{c}{ Dosage of CB (N330) } \\
\cline { 2 - 5 } & A & B & C & D \\
\hline $\mathrm{R}_{\mathrm{f}}(\%)$ & 95.7 & 95.1 & 92.0 & 91.8 \\
$\mathrm{R}_{\mathrm{r}}(\%)$ & 88.6 & 95.0 & 94.1 & 93.9 \\
\hline
\end{tabular}

To make distinct comprehensions of the shape memory process of TPI/LDPE/CB composites, a schematic diagram was proposed in Figure 3. Green and red colors represent TPI and LDPE portions, respectively. Meanwhile, lines with disorder and regular distribution stand for amorphous and crystalline regions of TPI/LDPE/CB composites, respectively. Black circles represent aggregation of CB particles. Crystalline regions of TPI/LDPE/CB composites were melted completely when samples were kept isothermally at $130{ }^{\circ} \mathrm{C}$ for $5 \mathrm{~min}$. Mechanical load was applied and temperatures were cooled down to $-20^{\circ} \mathrm{C}$, the temporary shape was formed and fixed. After the load removal and reheating process, specimens were returned to their permanent shapes again. 


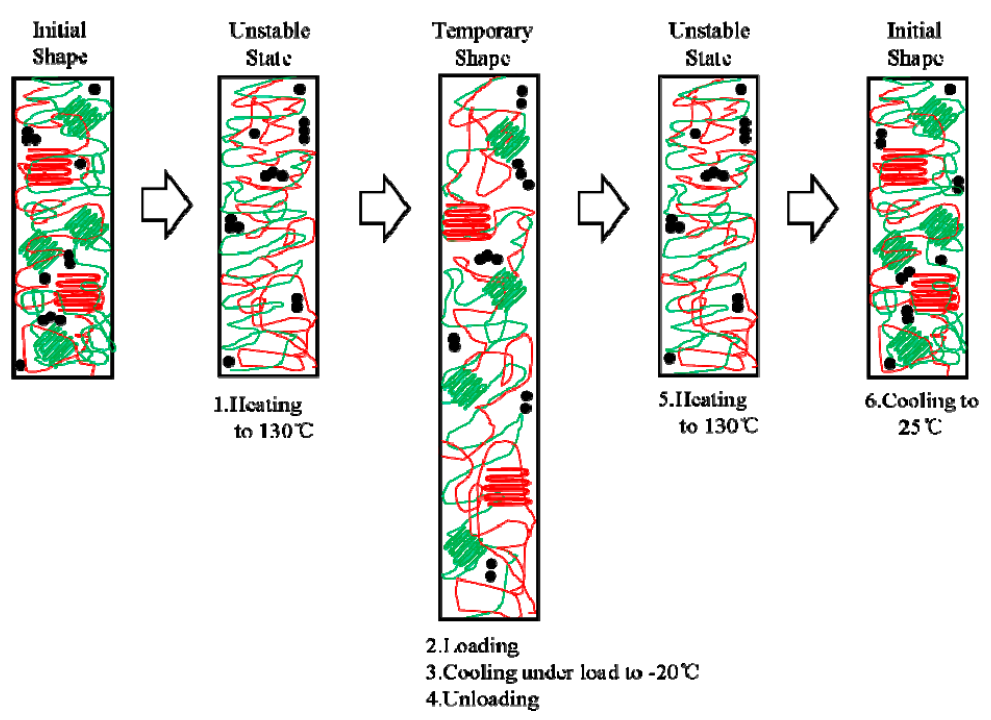

Figure 3. Schematic diagram of shape memory effect for TPI/LDPE/CB composites.

\section{Conclusions}

Shape memory composites of trans-1,4-polyisoprene (TPI) and low-density polyethylene (LDPE) with easily achievable transition temperatures were prepared by a simple physical blending method. Carbon black (CB) was introduced to improve the mechanical properties of the TPI/LDPE composites. The mechanical, cure, thermal and shape memory properties of the TPI/LDPE/CB composites were investigated in this study. In these composites, the crosslinked network generated in both the TPI and LDPE portions acted as a fixed domain, while the crystalline regions of the TPI and LDPE portions acted as a reversible domain in shape memory behavior. We found the mechanical properties of composites were promoted significantly with an increase of $C B$ content, accompanied with the deterioration of shape memory properties of composites. When CB dosage was $5 \mathrm{phr}$, the best shape memory property of composites was obtained with a shape fixity ratio of $95.1 \%$ and a shape recovery ratio of $95.0 \%$. However, the mechanical properties of TPI/LDPE composites reached their peak values when the CB dosage was $15 \mathrm{phr}$, of which the shape fixity ratio was $91.8 \%$ and the shape recovery ratio was $93.9 \%$, respectively.

Author Contributions: Funding acquisition, L.X. and W.F.; Investigation, L.X., H.G., W.B., W.F. and G.Q.; Project administration, G.Q. and Z.X.

Acknowledgments: Financial support from the National Natural Science Foundation of China (grant No. 51303092, 51573194) is gratefully acknowledged.

Conflicts of Interest: The authors declare no conflict of interest.

\section{References}

1. Pilate, F.; Toncheva, A.; Dubois, P.; Raquez, J.M. Shape-memory polymers for multiple applications in the materials world. Eur. Polym. J. 2016, 80, 268-294.

2. Liu, Y.; Lv, H.; Lan, X.; Leng, J.; Du, S. Review of electro-active shape-memory polymer composite. Compos. Sci. Technol. 2009, 69, 2064-2068.

3. Lu, H.; Yao, Y.; Huang, W.M.; Leng, J.; Hui, D. Significantly improving infrared light-induced shape recovery behavior of shape memory polymeric nanocomposite via a synergistic effect of carbon nanotube and boron nitride. Compos. Part B Eng. 2014, 62, 256-261. [CrossRef]

4. Kumar, U.N.; Kratz, K.; Wagermaier, W.; Behl, M.; Lendlein, A.J. Non-contact actuation of triple-shape effect in multiphase polymer network nanocomposites in alternating magnetic field. Mater. Chem. 2010, 20, 3404-3415. [CrossRef] 
5. Guo, W.; Lu, C.H.; Orbach, R.; Wang, F.; Qi, X.J.; Cecconello, A.; Seliktar, D.; Willner, I. pH-Stimulated DNA Hydrogels Exhibiting Shape-Memory Properties. Adv. Mater. 2015, 27, 73-78. [CrossRef] [PubMed]

6. Wu, T.; O'Kelly, K.; Chen, B. Poly (vinyl alcohol) particle-reinforced elastomer composites with water-active shape-memory effects. Eur. Polym. J. 2014, 53, 230-237. [CrossRef]

7. Wu, L.; Jin, C.; Sun, X. Synthesis, properties, and light-induced shape memory effect of multiblock polyesterurethanes containing biodegradable segments and pendant cinnamamide groups. Biomacromolecules 2010, 12, 235-241. [CrossRef] [PubMed]

8. Zhang, H.; Chen, Z.; Zheng, Z.; Zhu, X.; Wang, H. Shape memory polymer hybrids of SBS/dl-PLA and their shape memory effects. Mater. Chem. Phys. 2013, 137, 750-755. [CrossRef]

9. Nji, J.; Li, G. A biomimic shape memory polymer based self-healing particulate composite. Polymer 2010, 51, 6021-6029. [CrossRef]

10. Chen, J.; Fang, L.; Xu, Z.; Lu, C. Self-healing epoxy coatings curing with varied ratios of diamine and monoamine triggered via near-infrared light. Prog. Org. Coat. 2016, 101, 543-552. [CrossRef]

11. Habault, D.; Zhang, H.; Zhao, Y. Light-triggered self-healing and shape-memory polymers. Chem. Soc. Rev. 2013, 42, 7244-7256. [CrossRef]

12. Hu, J.; Meng, H.; Li, G.; Ibekwe, S.I. A review of stimuli-responsive polymers for smart textile applications. Smart Mater. Struct. 2012, 21, 053001. [CrossRef]

13. Liu, Y.; Du, H.; Liu, L.; Leng, J. Shape memory polymers and their composites in aerospace applications: A review. Smart Mater. Struct. 2014, 23, 23001. [CrossRef]

14. Chan, B.Q.Y.; Low, Z.W.K.; Heng, S.J.W.; Chan, S.Y.; Owh, C.; Loh, X.J. Recent advances in shape memory soft materials for biomedical applications. ACS Appl. Mater. Interfaces 2016, 8, 10070-10087. [CrossRef] [PubMed]

15. Xie, T. Recent advances in polymer shape memory. Polymer 2011, 52, 4985-5000. [CrossRef]

16. Hu, J.; Zhu, Y.; Huang, H.; Lu, J. Recent advances in shape-memory polymers: Structure, mechanism, functionality, modeling and applications. Prog. Polym. Sci. 2012, 37, 1720-1763. [CrossRef]

17. Liu, C.; Qin, H.; Mather, P.T. Review of progress in shape-memory polymers. J. Mater. Chem. 2007, 17, 1543-1558. [CrossRef]

18. Meng, H.; Li, G. A review of stimuli-responsive shape memory polymer composites. Polymer 2013, 54, 2199-2221. [CrossRef]

19. Leng, J.; Lan, X.; Liu, Y.; Du, S. Shape-memory polymers and their composites: stimulus methods and applications. Prog. Polym. Sci. 2011, 56, 1077-1135. [CrossRef]

20. Du, Z.; Zeng, X.M.; Liu, Q.; Schuh, C.A.; Gan, C.L. Superelasticity in micro-scale shape memory ceramic particles. Acta Mater. 2017, 123, 255-263. [CrossRef]

21. Eggeler, G.; Hornbogen, E.; Yawny, A.; Heckmann, A.; Wagner, M. Structural and functional fatigue of NiTi shape memory alloys. Mat. Sci. Eng. A 2004, 378, 24-33. [CrossRef]

22. Meng, Q.; Hu, J. A review of shape memory polymer composites and blends. Compos. Part A Appl. Sci. 2009, 40, 1661-1672. [CrossRef]

23. Zhao, Q.; Qi, H.J.; Xie, T. Recent progress in shape memory polymer: New behavior, enabling materials, and mechanistic understanding. Prog. Polym. Sci. 2015, 49, 79-120. [CrossRef]

24. Xia, L.; Wang, Y.; Lu, N.; Xin, Z. Facile fabrication of shape memory composites from natural Eucommia rubber and high density polyethylene. Polym. Int. 2017, 66, 653-658. [CrossRef]

25. Zhao, J.; Chen, M.; Wang, X.; Zhao, X.; Wang, Z.; Dang, Z.; Ma, L.; Hu, G.H.; Chen, F. Triple shape memory effects of cross-linked polyethylene/polypropylene blends with cocontinuous architecture. ACS Appl. Mater. Interfaces 2013, 5, 5550-5556. [CrossRef] [PubMed]

26. Xia, L.; Xian, J.; Geng, J.; Wang, Y.; Shi, F.; Zhou, Z.; Lu, N.; Du, A.; Xin, Z. Multiple shape memory effects of trans-1, 4-polyisoprene and low-density polyethylene blends. Polym. Int. 2017, 66, 1382-1388. [CrossRef]

27. Ma, L.; Zhao, J.; Wang, X.; Chen, M.; Liang, Y.; Wang, Z.; Yu, Z.; Hedden, R.C. Effects of carbon black nanoparticles on two-way reversible shape memory in crosslinked polyethylene. Polymer 2015, 56, 490-497. [CrossRef]

28. Gunes, I.S.; Cao, F.; Jana, S.C. Evaluation of nanoparticulate fillers for development of shape memory polyurethane nanocomposites. Polymer 2008, 49, 2223-2234. [CrossRef]

29. Rogers, N.; Khan, F. Characterization of deformation induced changes to conductivity in an electrically triggered shape memory polymer. Polym. Test. 2013, 32, 71-77. [CrossRef] 
30. Le, H.H.; Schoß, M.; Ilisch, S.; Gohs, U.; Heinrich, G.; Pham, T.; Radusch, H.J. CB filled EOC/EPDM blends as a shape-memory material: Manufacturing, morphology and properties. Polymer 2011, 52, 5858-5866. [CrossRef]

31. Qi, X.; Xiu, H.; Wei, Y.; Zhou, Y.; Guo, Y.; Huang, R.; Bai, H.; Fu, Q. Enhanced shape memory property of polylactide/thermoplastic poly (ether) urethane composites via carbon black self-networking induced co-continuous structure. Compos. Sci. Technol. 2017, 139, 8-16. [CrossRef]

32. Tchoudakov, R.; Breuer, O.; Narkis, M.; Siegmann, A. Conductive polymer blends with low carbon black loading: High impact polystyrene/thermoplastic elastomer (styrene-isoprene-styrene). Polym. Eng. Sci. 1997, 37, 1928-1935. [CrossRef]

33. Duan, L.; D'hooge, D.R.; Spoerk, M.; Cornillie, P.; Cardon, L. Facile and Low-Cost Route for Sensitive Stretchable Sensors by Controlling Kinetic and Thermodynamic Conductive Network Regulating Strategies. ACS Appl. Mater. Interfaces 2018, 10, 22678-22691. [CrossRef]

34. Duan, L.; Spoerk, M.; Wieme, T.; Cornillie, P.; Xia, H.; Zhang, J.; D'hooge, D.R. Designing formulation variables of extrusion-based manufacturing of carbon black conductive polymer composites for piezoresistive sensing. Compos. Sci. Technol. 2019, 171,78-85. [CrossRef]

35. Xie, T. Tunable polymer multi-shape memory effect. Nature 2010, 464, 267. [CrossRef] [PubMed]

36. Luo, X.; Mather, P.T. Triple-shape polymeric composites (TSPCs). Adv. Funct. Mater. 2010, 20, $2649-2656$. [CrossRef]

37. Kolesov, I.S.; Kratz, K.; Lendlein, A.; Radusch, H.J. Kinetics and dynamics of thermally-induced shape-memory behavior of crosslinked short-chain branched polyethylenes. Polymer 2009, 50, 5490-5498. [CrossRef]

(C) 2019 by the authors. Licensee MDPI, Basel, Switzerland. This article is an open access article distributed under the terms and conditions of the Creative Commons Attribution (CC BY) license (http://creativecommons.org/licenses/by/4.0/). 